Tohoku J. Exp. Med., 2007, 213, 261-268

\title{
Aging-Related Oxidative Stress in Healthy Humans
}

\author{
Víctor Manuel Mendoza-Núñez, ${ }^{1}$ Mirna Ruiz-Ramos, ${ }^{1}$ \\ Martha A. Sánchez-Rodríguez, ${ }^{1}$ Raquel Retana-Ugalde ${ }^{1}$ and \\ José LuIS MuÑOZ-SÁNCHEZ ${ }^{2}$ \\ ${ }^{1}$ Gerontology and Research Unit, FES-Zaragoza, UNAM, Mexico City, Mexico \\ ${ }^{2}$ Department of Biochemistry, National School of Biological Sciences (ENCB), IPN, Mexico City, \\ Mexico
}

Mendoza-Núñez, V.M., Ruiz-Ramos, M., SÁnchez-Rodríguez, M.A., Retana-Ugalde, R. and Muñoz-SÁNCHEZ, J.L. Aging-Related Oxidative Stress in Healthy Humans. Tohoku J. Exp. Med., 2007, 213 (3), 261-268 — Oxidative stress has been reported to increase with aging; however, the scientific evidence is controversial. We therefore aimed to analyze the relationship between aging and some markers of oxidative stress. A crosssectional and comparative study was carried out in a sample of 249 healthy subjects: (i) 25-29 years $(n=22)$; (ii) 30-39 years (24); (iii) 40-49 years (30); (iv) 50-59 years (48); (v) 60-69 years (60), and (vi) $\geqq 70$ years (65). We measured lipoperoxides and total antioxidant status in plasma and superoxide dismutase and glutathione peroxidase activities in erythrocytes. There was an age-related increase in lipoperoxides, which was evident in the comparison of the group of 25-29 years $(0.22 \pm 0.11 \mu \mathrm{mol} / \mathrm{l})$ with the group of 60-69 years $(0.38 \pm 0.18 \mu \mathrm{mol} / 1, p<0.01)$ and $\geqq 70$ years $(0.42 \pm 0.19, p<0.001)$. Conversely, the total antioxidant status showed an age-related decrease (25-29 years, $1.4 \pm 0.31 \mathrm{mmol} / \mathrm{l} \mathrm{vs}$ 60-69 years, $1.1 \pm 0.21$ and $\geqq 70$ years, $1.1 \pm 0.22, p<0.05$ for each). In erythrocytes, glutathione peroxidase activity showed an age-related decrease (25-29 years, 7,966 $\pm 1,813$ $\mathrm{UI} / 1$ vs $60-69$ years, 6,193 $\pm 2,235$ and $\geqq 70$ years, $6,547 \pm 2,307, p<0.001$ for each), whereas superoxide dismutase activity was similar in all age groups. Importantly, there was no age-related change in oxidative stress markers in subjects of $<60$ years. These findings suggest that age of $\geqq 60$ years may be associated with increased oxidative stress. - aging; oxidative stress; superoxide dismutase; lipoperoxides; antioxidant enzymes

(C) 2007 Tohoku University Medical Press

Human aging is an inexorable biological phenomenon characterized by a progressive decrease in physiological capacity and the reduced ability to respond to environmental stresses leads to increased susceptibility and vulnerability to disease. In this sense, it is pointed out that there are five common characteristics of aging in mammals: (i) increased mortality with age after maturation; (ii) changes in biochemical composition in tissues with age; (iii) progressive decrease in physiological capacity with age; (iv) reduced ability to respond adaptively to environmental stimuli with age; and (v) increased susceptibility and vulnerability to disease (Troen 2003). At the same time, it has been proposed that aging is the consequence of cell oxidative damage, in

Received June 14, 2007; revision accepted for publication September 26, 2007.

Correspondence: Víctor Manuel Mendoza-Núñez, Gerontology and Research Unit, FES-Zaragoza, UNAM.

Batalla 5 de mayo s/n, Esq. Fuerte de Loreto, Col. Ejército de Oriente, 09230, Mexico City, Mexico.

e-mail:mendovic@servidor.unam.mx 
particular the accumulation of mtDNA mutations, determined by the imbalance of the rate of reactive oxygen species production and degradation induced by the antioxidant defense systems, named oxidative stress (Camougrand and Rigoulet 2001; Barja 2004; Rizvi et al. 2006).

Harman (1956) proposed the free radicals theory, which arises from aging, as the result of accumulation of oxidative-damaged macromolecules (protein lipids, DNA) and consequently of cells and tissues as the result of the aerobic metabolism to which individuals are exposed throughout their lifetime. In this regard, it has been pointed out that there is a correlation among longevity, metabolic rate, and antioxidant protective activity. Similarly, it has been demonstrated that an increase in antioxidant enzyme expression in experimental animals produces a significant increase in longevity (Wickens 2001).

On the other hand, Sohal et al. (1995) demonstrated that overexpression of superoxide dismutase enzymes and catalase in Drosophila melanogaster produces a $30 \%$ increase in longevity accompanied by a diminution of oxidative damage to proteins. Similarly, oxidative stress has been implicated in the pathogenesis of several diseases whose incidence increases as age increases. Notwithstanding this, it is not completely established whether reactive oxygen species are the cause or the effect of aging and of certain chronic diseases. This is because in vitro studies have shown that free radicals are able to propitiate degeneration and neuronal death, but damaged tissue itself can induce reactive oxygen species production (Fukagawa 1999).

Evidence has also demonstrated that 8hydroxy-2'-deoxyguanosine (8-OHdG) levels correlate negatively with the potential maximum longevity of diverse animals, in addition to the fact that oxidative damage to DNA increases according to age (Barja 2002). In this respect, our investigation group, by means of the comet assay technique has that subjects $\geqq 70$ years of age compared with those aged between 60 and 69 years present nearly twice the risk for DNA damage (Mendoza-Núñez et al. 1999).

Nonetheless, King et al. (1997) found a simi- larity in the DNA damage and repair capacity in subjects 35-39 years vs 75-80 years of age, in addition to significantly higher levels of glutathione peroxidase, catalase and ceruloplasmin in a group of elderly persons. Likewise, Betti et al. (1994) reported that these authors observed no statistically significant differences in DNA damage related to increase in age. Thus, the aim of the present study is to determine the relationship of age with biological markers of oxidative stress in healthy subjects from Mexico City, Mexico.

\section{Subjects ANd Methods}

Subjects and design

A cross-sectional and comparative study was carried out in a sample of 249 healthy subjects: i) 25-29 years $(n=22)$; ii) $30-39$ years $(n=24)$ years; iii) 40-49 years (30); iv) 50-59 years (48); v) 60-69 years (60) and vi) $\geqq$ 70 years $(n=65)$. We measured lipoperoxides by thiobarbituric acid reacting substances (TBARS) assay, erythrocyte superoxide dismutase (SOD), glutathione peroxidase (GPx) and total plasma antioxidant status (TAS) with Randox Laboratories, Ltd kits.

None of the subjects studied had been taking antioxidant supplementation (vitamins or minerals) for at least 6 months previously and none smoked or had acute or chronic diseases or were receiving prescription medications. All individuals were healthy (without arterial hypertension, diabetes mellitus, or cancer) and well nourished. Older subjects ( $\geqq 60$ years) had body mass index (BMI) of $23.1-27 \mathrm{~kg} / \mathrm{m}^{2}$, their Mini Nutritional Assessment score was $>23.5$, their caloric intake was between 2,000 and 2,500 kcal per day, their alimentation had the nutrient requirements (protein, fat, carbohydrate, vitamins, and minerals) consistent with the recommended dietary allowance (RDA) measured by 24 -hr dietary recalls, and their serum albumin was $>35 \mathrm{~g} / \mathrm{l}$. Adult subjects (25-59 years) had BMI of $22.1-25 \mathrm{~kg} / \mathrm{m}^{2}$, their caloric intake was between 2,200 and 2,800 kcal per day, their alimentation had the nutrient requirements (protein, fat, carbohydrate, vitamins, and minerals) consistent with the RDA measured by 24-hr dietary recalls, and their serum albumin was > $35 \mathrm{~g} / \mathrm{l}$ (Barrocas et al. 1995; Ervin 1998; Vellas et al. 2000). The physical activity was similar between groups of older subjects and adult subjects; this was measured with a physical activity questionnaire (Bertoldi et al. 2006). The subjects agreed to participate in the study after giving their informed consent. The Ethics Committee of the Universidad Nacional Autó 
noma de México (Zaragoza Campus) approved the research protocol for this study.

\section{Blood sampling and preparation}

Blood samples were collected by venopuncture after a 12-hr fasting period and were placed in vacutainer and siliconized test tubes containing a separating gel without additives. Heparin and ethylenedinitrilotetraacetic acid (EDTA) were used as anticoagulant agents. Blood samples containing heparin were analyzed using complete hemoglobin test protocol (including hemoglobin, hematocrit, and leukocyte counts). Likewise TBARS, TAS, SOD, GPx activities. The samples without anticoagulant agents were centrifuged at $3,500 \mathrm{rpm}$ for $10 \mathrm{~min}$ at $15^{\circ} \mathrm{C}-20^{\circ} \mathrm{C}$ with a centrifuge Eppendorf 5804 (Hamburg, Germany); the serum obtained was subjected to the following tests: glucose, blood urea nitrogen (BUN), creatinine, urate, albumin, cholesterol, triglycerides, and high-density lipoprotein cholesterol (HDL-C) concentrations. These tests were used as screening measurements for diagnosis of clinically healthy subjects.

From the samples with heparin, $600 \mu 1$ of the whole blood were kept for red blood cell (SOD), $100 \mu 1$ for red blood cell (GPx). Each sample later was centrifuged at $3,500 \mathrm{rpm}$ during $10 \mathrm{~min}$ at $15^{\circ} \mathrm{C}-20^{\circ} \mathrm{C}$ a centrifuge Eppendorf 5804 (Hamburg, Germany). From the obtained plasma $100 \mu 1$ were taken for TAS and $1,000 \mu 1$ for TBARS.

\section{Blood and biochemical analyses}

Hemoglobin levels were measured by the cyanomethahemoglobin reaction procedure (cut-off points: males, 12.17-17.26 g/dl, females, 11.48-16.25 g/dl). Hematocrit levels were assessed by the microhematocrit procedure (cut-off points: males, $38-52 \%$, females, $36-51 \%$ ). Leukocyte counts were done by the Newbauer chamber procedure (cut-off points: $3,500-10,650 / \mathrm{mm}^{3}$ ).

Glucose, urea, creatinine, urate, albumin, cholesterol, triglycerides, and HDL-C concentration levels were determined using an Autoanalyzer Vitalab Eclipse Merck (Dieren, The Netherlands). In particular, glucose levels were measured by the glucose oxidase method (cut-off points: $63-120 \mathrm{mg} / \mathrm{dl}$ ), urea levels by the Berthelot urease method (cut-off points: $9.5-47 \mathrm{mg} / \mathrm{dl}$ ), creatinine levels by the Jaffe method without deproteinization (cut-off points: males, 0.3-1.5 mg/dl; females, $0.3-1.3 \mathrm{mg} / \mathrm{dl}$ ), and urate levels by the uricase colorimetric method (cutoff points: males, $2.9-8.88 \mathrm{mg} / \mathrm{dl}$; females, $2.5-8.7 \mathrm{mg} /$ dl). Albumin levels were measured with the bromocresol green technique (3.23-4.03 g/dl).

Cholesterol was analyzed using CHOD-PAP technique (cut-off points: $168-200 \mathrm{mg} / \mathrm{dl}$ ), triglycerides by GPO-Trinder technique (cut-off points: $89-190 \mathrm{mg} / \mathrm{dl}$ ), whereas HDL was assessed using the same technique used to analyze cholesterol after precipitation of low- and very low-density lipoproteins using a phosphotungstic acid/magnesium chloride solution (cut-off points: 42-77 $\mathrm{mg} / \mathrm{dl})$.

All reagents used in biochemical tests were obtained from Randox Laboratories, Ltd. (Crumlin, Co., Antrim, UK). Cut-off points for reference values were determined at the Gerontologic Clinical Research Laboratory of Universidad Nacional Autonoma de México (UNAM), Zaragoza Campus, Mexico City (Sánchez-Rodríguez et al. 1998).

\section{Plasma TBARS}

The TBARS assay was prepared as described by Jentzsch et al. (1996). In the TBARS assay, one molecule of malondialdehyde reacts with two molecules of thiobarbituric acid (TBA) and thereby produces a pink pigment with absorption peak at $535 \mathrm{~nm}$. Amplification of peroxidation during the assay is prevented by the addition of the chain-breaking antioxidant, butyril hidroxy toluene (BHT).

Plasma $(400 \mu \mathrm{l})$ or malondialdehyde (MDA) standard (0.2-4 $\mu \mathrm{mol} / \mathrm{l})$ prepared by hydrolysis of 1,1,3,3tetramethoxypropane (Sigma Chemical Co., St. Louis, MO, USA) was mixed with $400 \mu 1$ orthophosphoric acid (0.2 mol/l) (Sigma Chemical Co.) and $50 \mu 1$ BHT (2 mmol/l) (Sigma Chemical Co.) in $12 \times 72 \mathrm{~mm}$ tubes. A total of $50 \mu 1 \mathrm{TBA}$ reagent $(0.11 \mathrm{~mol} / 1$ in $0.1 \mathrm{~mol} / 1$ $\mathrm{NaOH}$ ) (Fluka Chem., Buchs, Switzerland) then has been added and the contents were mixed. Subsequently, the contents were incubated at $90^{\circ} \mathrm{C}$ for $45 \mathrm{~min}$ in a water bath. The tubes then were kept on ice to prevent further reaction. TBARS were extracted once with $1,000 \mu 1$ $n$-butanol (Sigma Chemical Co.). The upper butanol phase was read at $535 \mathrm{~nm}$ and at $572 \mathrm{~nm}$ to correct for baseline absorption in UV-spectrophotometer Shimadzu UV-1601 (Shimadzu, Kyoto). MDA equivalents (TBARS) were calculated by the difference in absorption at the two wavelengths and quantification was done with calibration curve.

Plasma TAS

Antioxidant quantification was done using 2, 2' azino-bis (3-ethylbenzthiazoline-6-sulfonic acid) $\left(\mathrm{ABTS}^{+}\right.$) radical formation kinetics (Randox 
Laboratories, Ltd., Crumlin Co., UK). The antioxidants present in plasma suppressed the bluish-green staining of the $\mathrm{ABTS}^{+}$cation, which was proportional to the antioxidant concentration level. The kinetics was measured at $600 \mathrm{~nm}$ with UV-spectrophotometer Shimadzu UV-1601 (Shimadzu).

\section{Red blood cell SOD}

The method uses xantine and xantine oxidase (XOD) to generate superoxide radicals, which react with 2-(4-iodophenyl)-3-(4-nitrophenol)-5-phenyltetrazolim chloride to form a red formazan dye. SOD activity was measured by degree of inhibition of the reaction (Randox Laboratories Ltd.). The kinetics was measured at 505 $\mathrm{nm}$ with UV-spectrophotometer Shimadzu UV-1601 (Shimadzu).

\section{Red blood cell GPX}

In the presence of glutathione reductase and NADPH, the oxidation of glutathione (GSH) by cumene hydroperoxide is catalyzed by GPx. Oxidized glutathione (GSSG) is immediately converted into the reduced form with a subsequent oxidation of NADPH to NADP+ (Randox Laboratories, Ltd.). Decrease in absorbance was measured at $340 \mathrm{~nm}$ with UV-spectrophotometer Shimadzu UV-1601 (Shimadzu).

Statistical analysis

Data were processed by standard statistical software
SPSS 14.0 (SPSS Inc., Chicago, IL, USA). Descriptive statistics are analyzed by means \pm S.E. Results were analyzed using analysis of variance (ANOVA) and Tukey test post hoc. A $p$ value $<0.05$ was considered significant.

\section{Results}

The results showed that LPO serum levels were significantly higher in older subjects than in the younger ones of the same sex (young male, $0.305 \pm 0.14$ vs older male $0.385 \pm 0.19, p<0.05$; young female, $0.314 \pm 0.15$ vs older female, 0.400 $\pm 4.41 \mu \mathrm{mol} / 1, p<0.05)$, however, significant differences were not observed between sex by age group.

At the same time, GPx and TAS were significantly lower in older males than in young males (GPx: young male, 7,661 $\pm 1,976$ vs older male, $6,217 \pm 2,165 \mathrm{UI} / 1, p<0.05$; TAS: young male, $1.35 \pm 0.26$ vs $1.19 \pm 0.18 \mathrm{mmol} / 1, p<0.05)$, nevertheless in females there were no significant differences $(p>0.05)$. The SOD activity was maintained significantly without change, with aging (Table 1).

Oh the other hand, significant differences were not found in oxidative stress markers between premenopausal versus postmenopausal women: LPO, premenopausal, $309 \pm 0.06$ vs post-

TABLE 1. Body mass index, markers oxidative stress, urate, albumin and cholesterol by age-group and sex.

\begin{tabular}{|c|c|c|c|c|}
\hline \multirow{3}{*}{ Subjects number } & \multicolumn{2}{|c|}{ Young adults (25-59 years) } & \multicolumn{2}{|c|}{ Older adults ( $\geqq 60$ years $)$} \\
\hline & Male & Female & Male & Female \\
\hline & 47 & 77 & 38 & 87 \\
\hline Body mass index (BMI) & $26.2 \pm 1.94$ & $26.7 \pm 4.95$ & $26.5 \pm 3.85$ & $28.3 \pm 4.41$ \\
\hline Lipoperoxides (LPO $\mu \mathrm{mol} / \mathrm{l}$ ) & $0.305 \pm 0.14$ & $0.314 \pm 0.15$ & $0.385 \pm 0.19^{a}$ & $0.400 \pm 0.18^{b}$ \\
\hline Total antioxidant status (TAS mmol/l) & $1.35 \pm 0.26$ & $1.17 \pm 0.24$ & $1.19 \pm 0.18^{c}$ & $1.13 \pm 0.22$ \\
\hline Glutathione peroxidase (GPx UI/l) & $7,661 \pm 1,97$ & $7,286 \pm 2,146$ & $6,217 \pm 2,165^{\mathrm{d}}$ & $6,366 \pm 2,310$ \\
\hline Superoxide dismutase (SOD UI/l) & $174 \pm 10$ & $173 \pm 11$ & $176 \pm 16$ & $171 \pm 17$ \\
\hline Urate $(\mathrm{mg} / \mathrm{dl})$ & $6.2 \pm 1.3$ & $4.6 \pm 1.5$ & $5.8 \pm 1.8$ & $4.7 \pm 1.6$ \\
\hline Albumin $(\mathrm{g} / \mathrm{dl})$ & $4.5 \pm 0.35$ & $4.3 \pm 0.43$ & $4.2 \pm 0.48$ & $4.1 \pm 0.49$ \\
\hline Cholesterol (mg/dl) & $206 \pm 37$ & $200 \pm 37$ & $211 \pm 50$ & $228 \pm 84^{\mathrm{e}}$ \\
\hline
\end{tabular}

Data are mean values \pm S.E.; ANOVA with Tukey test. LPO: a Male young adults vs older adults, $p<$ 0.05 ; ${ }^{b}$ Female young adults vs older adults, $p<0.05$. TAS: 'Male young adults vs older adults, $p<0.05$. GPx: ${ }^{\mathrm{d}}$ Male young adults versus older adults, $p<0.05$. Cholesterol: ${ }^{\mathrm{F}} \mathrm{Female}$ young adults vs older adults, $p<0.05$. 
menopausal $384 \pm 0.02 \mu \mathrm{mol} / 1, p>0.05$; GPx, premenopausal $7,700 \pm 482$ vs postmenopausal $6,580 \pm 383 \mathrm{UI} / 1, p>0.05$; TAS, premenopausal $1.18 \pm 0.08$ vs postmenopausal $1.13 \pm 0.03$ $\mathrm{mmol} / 1, p>0.05$; SOD, premenopausal $176 \pm 4.0$ vs postmenopausal $171 \pm 2.9 \mathrm{UI} / 1, p>0.05$.

In the ANOVA by age group, the LPO showed an age-related increase, in the post-hoc Tukey analysis it was found differences in the comparison of the groups of 25-29 years with $60-69$ and $\geqq 70$ years $(25-29$ years, $0.22 \pm 0.11$ vs $60-69$ years, $0.38 \pm 0.18, p<0.01$, and $\geqq 70$ years, $0.42 \pm 0.19 \mu \mathrm{mol} / 1, p<0.001)$. At the same time, TAS activity presented an age-related decrease, which was observed in the post-hoc analysis in the comparison among groups of 25-29 years with $60-69$ and $\geqq 70$ years $(25-29$ years, $1.4 \pm 0.31$ vs $60-69$ years, $1.1 \pm 0.21, p<$ 0.05 , and $\geqq 70$ years, $1.1 \pm 0.22 \mathrm{mmol} / 1, p<0.05)$. Also GPx showed an age-related decrease, which was observed in the post-hoc analysis in the comparison among groups of 25-29 years with 60-69 and $\geqq 70$ years $(25-29$ years, $7,966 \pm 1,813$ vs 60-69 years, 6,193 $\pm 2,235, p<0.001$, and $\geqq 70$ years, 6,547 $\pm 2,307 \mathrm{UI} / 1, p<0.001)$, however, SOD activity was similar in all groups (Table 2).

Fig. 1 shows a significant increase of LPO in subjects $\geqq 60$ years in comparison with $25-29$ years group, and at the same time an age-related decrease of total antioxidant status and GPx, although there are no significant differences between groups $<60$ years in these parameters. The SOD activity in erythrocytes does not show any age-related changes.

\section{Discussion}

During old age, generation of free radicals increases. Such a biochemical alteration increases the risk of oxidative damage to macromolecules (DNA, proteins, carbohydrates, and lipids), favoring the presence or complications of a great number of acute and chronic diseases including the following diseases: diabetes mellitus, atherosclerosis; distinct cancer types; chronic obstructive pulmonary disease, bronchial asthma, cataracts, macular degeneration, human immunodeficiency virus (HIV)-associated infection, rheumatoid arthritis, Alzheimer's disease, obstructive sleep apnea, acute myocardial infarct, cerebrovascular disease, ischemia-reperfusion, sepsis, renal insufficiency, pancreatitis, and periodontal disease (Knight 1999).

Human cells suffer from 10,000 hits of free radicals daily. This number increases with aging, and joined to certain pro-oxidant factors such as smoking, alcoholism, environmental contamination, ultraviolet radiation, insufficient hours of sleep, extenuating physical activity, inadequate nutrition, masculine gender, drug consumption, and psychological stress determine the genesis of chronic diseases during old age (Ames et al. 1993; Hicks et al. 1996; D'Almeida et al. 1998;

TABLE 2. Biological markers of oxidative stress by age groups.

\begin{tabular}{lcccccc}
\hline & \multicolumn{5}{c}{ Age groups (years) } \\
\cline { 2 - 7 } & $25-29$ & $30-39$ & $40-49$ & $50-59$ & $60-69$ & $\geqq 70$ \\
\hline $\begin{array}{l}\text { Lipoperoxides } \\
\text { (LPO } \mu \text { mol/l) }\end{array}$ & $0.22 \pm 0.11$ & $0.28 \pm 0.11$ & $0.31 \pm 0.12$ & $0.31 \pm 0.14$ & $0.38 \pm 0.18^{\mathrm{a}}$ & $0.42 \pm 0.19^{\mathrm{b}}$ \\
$\begin{array}{l}\text { Total antioxidant status } \\
\text { (TAS mmol/l) }\end{array}$ & $1.4 \pm 0.31$ & $1.3 \pm 0.26$ & $1.2 \pm 0.28$ & $1.2 \pm 0.25$ & $1.1 \pm 0.21^{\mathrm{c}}$ & $1.1 \pm 0.22^{\mathrm{d}}$ \\
$\begin{array}{l}\text { Glutathione peroxidase } \\
\text { (GPx UI/l) }\end{array}$ & $7,966 \pm 1,813$ & $7,660 \pm 2,316$ & $7,827 \pm 1,637$ & $6,981 \pm 2,226$ & $6,193 \pm 2,235^{\mathrm{e}}$ & $6,547 \pm 2,307^{\mathrm{f}}$ \\
$\begin{array}{l}\text { Superoxide dismutase } \\
\text { (SOD UI/l) }\end{array}$ & $178 \pm 14$ & $173 \pm 12$ & $174 \pm 8$ & $172 \pm 12$ & $173 \pm 15$ & $172 \pm 20$ \\
\hline
\end{tabular}

Data are mean values \pm S.E.; ANOVA with Tukey test. LPO: ${ }^{2} 25-29$ vs $60-69$ years, $p<0.01$; ${ }^{\text {b }} 25-29$ vs $\geqq 70$ years, $p<0.001$. TAS: ${ }^{c} 25-29$ vs $60-69$ years, $p<0.05$; ${ }^{\mathrm{d}} 25-29$ vs $\geqq 70$ years, $p<0.05$. GPx: ${ }^{\mathrm{e}} 25-29$ vs $60-60$ years, $p<0.001$; ${ }^{\mathrm{f}} 25-29$ vs $\geqq 70$ years, $p<0.001$. 


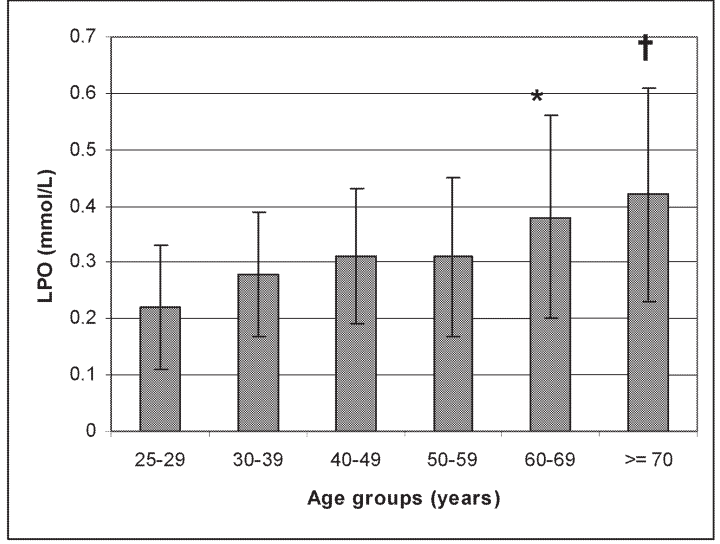

A. Lipoperoxides

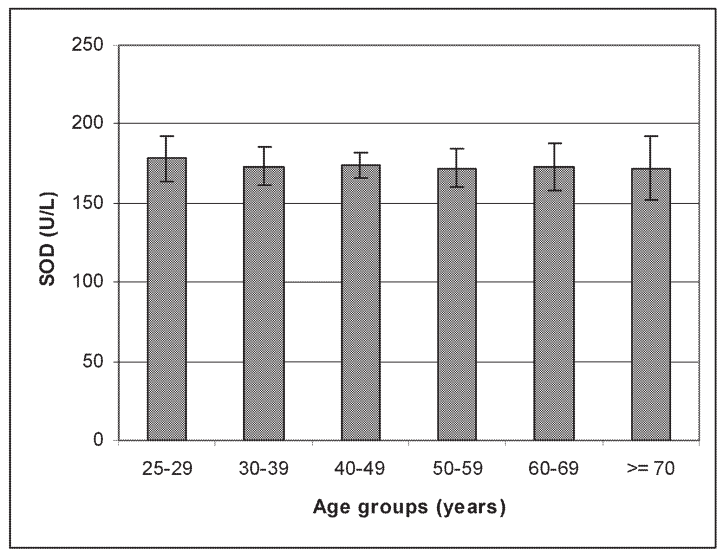

C. Superoxide Dismutase

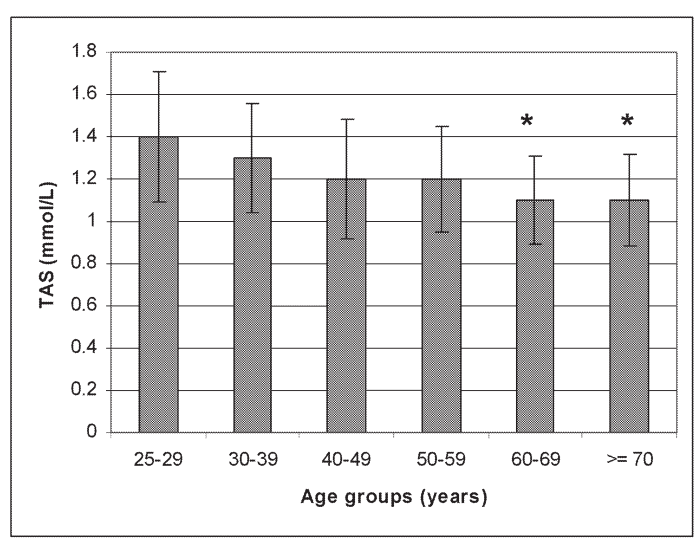

B. Total Antioxidant Status

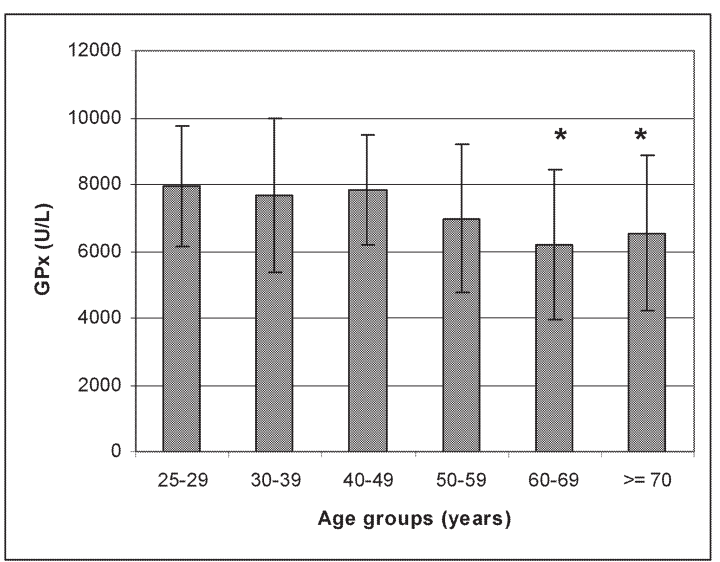

D. Glutathione Peroxidase

Fig. 1. Lipoperoxides, total antioxidant status, supeoxide dismutase and glutation peroxidase activities by age-group.

A: Lipoperoxides levels are similar in the groups of 30 to 59 years, however after 60 years the increase is patent in comparison with 25-29 years group $* p<0.01 ; \dagger p<0.001$. B: Total antioxidant status shows significant differences between $25-29$ years group vs $\geqq 60$ years groups $* p<0.05$. C: Superoxide dismutase does not show significant differences between groups. D: Glutathione peroxidase shows significant differences between $25-29$ years group vs $\geqq 60$ years groups $* p<$ 0.001 .

Mastaloudis et al. 2001; Mendoza-Núñez et al. 2001).

In this study, we found plasma LPO levels were significantly higher in the group of elderly persons, as compared with the younger group. These findings coincide with those reported by Özbay and Dülger (2002). Nevertheless, it has also been reported that free radical levels do not increase according to age when no pro-oxidant factors such as smoking are associated (Bridges et al. 1993). In this respect, both studies are crosssectional, therefore it is necessary to carry out longitudinal studies to corroborate the influence of aging per se on free radicals levels considering the dynamic influence of all pro-oxidant factors linked with lifestyles and environment.

There is evidence that efficiency of the anti-oxidant system decreases after 45 years of age (Jones et al. 2002). However, our data did not show a significant age-related progressive increase of oxidative stress in subjects of $<60$ years. We found a significant diminution in GPx and anti-oxidant levels in persons $>60$ years in comparison with group of 25-29 years, which 
agrees with the increase in LPO levels, suggesting that older subjects have higher risk of oxidative stress than younger and consequently greater vulnerability for the presence of chronic-disease in old age.

The age-related changes in SOD activity are controversial. Andersen et al. (1997) reported the age-related decrease in SOD activity, whereas Mariani et al. (2006) showed an erythrocyte SOD activity was higher in nonagenarians than subjects of 60-89 years. The present study showed that the SOD activity remains unchanged during aging. This could be because of an adaptive process that develops in the population residing in Mexico City, where the population is exposed to the environmental contamination (Medina-Navarro et al. 1997).

In present study significant differences were not observed in the biological markers of oxidative stress by sex, which is contradictory to several studies (Christensen et al. 2001; Habif et al. 2001). Gender is a profound determinant of aging and lifespan, however, little is known about gender differences in free radical homeostasis. Oxidative stress is proposed as a key element in the multifactorial process of aging and it is predicted that the gender that lives longer must have lower levels of oxidative stress. Several hypotheses have been proposed for sex differences in longevity, including the active female immune function, the protective effect of estrogen, compensatory effects of the second X chromosome, reduction in the activity of growth hormone and the insulin-like growth factor 1 signaling cascade, and the influence of oxidative stress on aging and disease (Christensen et al. 2001; Austad 2006).

Bednarek-Tupikowska et al. (2004) showed that postmenopausal women have higher LPO and lower TAS than the control group. We performed a comparison between biological markers of oxidative stress of premenopausal versus postmenopausal women; the LPO levels were higher and GPx activity lower in the postmenopausal than premenopausal women, although the differences were not significantly. This suggests that hormonal factor per se does not have significant influence on oxidative stress.

It is indispensable to establish parameters that allow differentiating degrees of oxidative stress, because the oxidative stress does not necessarily represent a disease risk on account of the fact that free radicals also possess a physiological function (Finkel and Holbrook 2000; Dröge 2002). Thus, it would be advantageous to differentiate between aging on account of oxidative stress and moderate or severe oxidative stress, which could be useful as biological marker of chronic-disease and accelerate aging.

On the other hand, the preventive indication of antioxidant supplements, such as vitamins A, C, and E, lipoic acid, and melatonin (Kripke et al. 1998; Savitha and Panneerselvam 2007), in healthy individuals of 45 years or more is not justified, considering the fact that before 60 years old there was no significant increase in oxidative stress.

Finally, our data suggest that aging per se increases oxidative stress, although it does not affect all parameters, which may reflect the differences in the environmental and lifestyle factors of the studied subjects. It must be considered as limitations of the study that this is a crosssectional study with older adults who are survivors and are not representative of all older people. Therefore, it is necessary to carry out cross-longitudinal studies in cohorts to confirm our findings.

\section{Acknowledgments}

This study was supported by grant: Universidad Nacional Autónoma de México (UNAM) DGAPA, PAPIIT IN310305.

\section{References}

Ames, B.N., Shigenago, M.K. \& Hagen, T.M. (1993) Oxidants, antioxidants, and degenerative diseases of aging. Proc. Natl. Acad. Sci. USA, 90, 7915-7922.

Andersen, H.R., Nielsen, J.B., Nielsen, F. \& Grandjean, P. (1997) Antioxidative enzyme activities in human erythrocytes. Clin. Chem., 43, 562-568.

Austad, S.N. (2006) Why women live longer than men: sex differences in longevity. Gend. Med., 3, 79-92.

Barja, G. (2002) Rate of generation of oxidative stress-related damage and animal longevity. Free Radic. Biol. Med., 33, 1167-1172.

Barja, G. (2004) Free radicals and aging. Trends Neurosci., 27, 595-600.

Barrocas, A., Belcher, D., Champagne, C. \& Jastram, C. (1995) 
Nutrition assessment practical approaches. Clin. Geriatr. Med., 11, 675-708.

Bednarek-Tupikowska, G., Tupikowski, K., Bidzinska, B., Bohdanowics-Pawlak, A., Antonomicz-Juchniewicz, J., Kosowska, B. \& Milewicz, A. (2004) Serum lipid peroxides and total antioxidant status in postmenopausal women on hormone replacement therapy. Gynecol. Endocrinol., 19, 57-63.

Bertoldi, A.D., Hallal, P.C. \& Barros, A.J. (2006) Physical activity and medicine use: evidence from a populationbased study. BMC Public Health, 6, 224.

Betti, C., Davini, T., Giannessi, L., Loprieno, N. \& Barale, R. (1994) Microgel electrophoresis assay (comet test) and SCE analysis in human lymphocytes from 100 normal subjects. Mutat. Res., 307, 323-333.

Bridges, A.B., Scott, N.A., Pary, G.J. \& Belch, J.J. (1993) Age, sex, cigarette smoking and indices of free radical activity in healthy humans. Eur. J. Med., 2, 205-208.

Camougrand, N. \& Rigoulet, M. (2001) Aging and oxidative stress: studies of some genes involved both in aging and in response to oxidative stress. Resp. Physiol., 128, 393-401.

Christensen, K., Orstavic, K.H. \& Vaupel, J.W. (2001) The X chromosome and the female survival advantage. Ann. NY Acad. Sci., 954, 175-183.

D’Almeida, V., Lobo, L.L., Hipólide, D.C., de Oliveira, A.C., Nobrega, J.N. \& Tufik, S. (1998) Sleep deprivation induces brain region-specific decreases in glutatione levels. Neuro. Report, 9, 2853-2856.

Dröge, W. (2002) Free radicals in the physiological control of cell function. Physiol. Rev., 82, 48-80.

Ervin, R.B. (1998) Using encoding and retrieval strategies to improve 24-hour dietary recalls among older adults. J. Am. Diet. Assoc., 98, 989-994.

Finkel, T. \& Holbrook, N.J. (2000) Oxidants, oxidative stress an the biology of ageing. Nature, 408, 239-247.

Fukagawa, N.K. (1999) Is oxidative stress a marker or is it causal? Proc. Soc. Exp. Biol. Med., 222, 293-298.

Habif, S., Mutaf, I., Turgan, N., Onur, E., Duman, C., Özmen, D. \& Bayindir, O. (2001) Age and gender dependent alterations in the activities of glutathione related enzymes in healthy subjects. Clin. Biochem., 34, 667-671.

Harman, D. (1956) Aging: A theory based on free radical and radiation chemistry. J. Gerontol., 11, 298-300.

Hicks, J.J., Medina-Navarro, R., Guzmán-Grenfell, A., Wacher, N. \& Lifshitz, A. (1996) Possible effect of air pollutants (Mexico City) on superoxide dismutase activity and serum lipoperoxides in the human adult. Arch. Med. Res., 27, $145-149$

Jentzsch, A.M., Bachmann, H., Fürst, P. \& Biesalski, H.K. (1996) Improved analysis of malondialdehyde in human body fluids. Free Radic. Biol. Med., 20, 251-256.

Jones, D.P., Mody, V.C., Carlson, J.L., Lynn, M.J. \& Sternberg, P. (2002) Redox analysis of human plasma allows separation of pro-oxidant events of aging from decline in antioxidant defenses. Free Radic. Biol. Med., 33, 1290-1300.

King, C.M., Bristow-Craig, H.E., Gillespie, E.S. \& Barnett, Y.A. (1997) In vivo antioxidant status, DNA damage, mutation and DNA repair capacity in cultured lymphocytes from healthy 75-to 80 years-old humans. Mutat. Res., 377, 137-147.

Knight, J.A. (1999) Free radicals, antioxidants, aging, \& disease. AACC PRESS. Washington, D.C.

Kripke, D.F., Elliot, J.A., Younstedt, S.D. \& Smith, J.S. (1998) Melatonin: marvel or marker. Ann. Med. Int., 30, 81-87.

Mariani, E., Cornacchiola, V.M.C., Polidori, M.C., Mangialasche, F., Malavolta, M., Cecchetti, R., Bastiani, P., Baglioni, M., Mocchegiani, E. \& Mecocci, P. (2006) Antioxidantenzyme activities in healthy old subjects: influence of age, gender and zinc status. Biogerontology, 7, 391-398.

Mastaloudis, A., Leonard, S.W. \& Traber, M.G. (2001) Oxidative stress in athletes during extreme endurence exercise Free Radic. Biol. Med., 31, 911-922.

Medina-Navarro, R., Lifshitz, A., Wacher, N. \& Hicks, J.J. (1997) Changes in human serum antioxidant capacity and peroxidation after four months of exposure to air pollutants. Arch. Med. Res., 28, 205-208.

Mendoza-Núñez, V.M., Retana-Ugalde, R., Sánchez-Rodríguez, M.A. \& Altamirano-Lozano, M.A. (1999) DNA damage in lymphocytes of elderly patients in relation with total antioxidant levels. Mech. Ageing Dev., 108, 9-23.

Mendoza-Núñez, V.M., Sánchez-Rodríguez, M.A., RetanaUgalde, R., Vargas-Guadarrama, L.A. \& AltamiranoLozano, M.A. (2001) Total antioxidant levels, gender, and age as risk factors for DNA damage in lymphocytes of elderly. Mech. Ageing Dev., 122, 835-847.

Özbay, B. \& Dulger, H. (2002) Lipid peroxidation and antioxidant enzymes in Turkish population: relation to age, gender, exercise, and smoking. Tohoku J. Exp. Med., 197, 119-124.

Rizvi, S.I., Jha, R. \& Maurya, P.K. (2006) Erythrocyte plasma membrane redox system in human aging. Rejuv. Res., 9, 470-474.

Sánchez-Rodríguez, M., Mendoza-Núñez, V.M., GarcíaSánchez, A., González-González, B., Rodríguez-Torres, E. \& González-Obregón A. (1998) Valores de referencia para una población de ancianos y adultos de la Ciudad de México. Parámetros bioquímicos y hematológicos. Acta Bioquim. Clin. Latinoam., 32, 812-821.

Savitha, S. \& Panneerselvam, C. (2007) Mitigation of agedependent oxidative damage to DNA in rat heart by carnitine and lipoic acid. Mech. Ageing Dev., 128, 206-212.

Sohal, R.S., Sohal, B.H. \& Orr, W.C. (1995) Mitochondrial superoxide and hydrogen peroxide generation, protein oxidative damage and longevity in different speciesof files. Free Radic. Biol. Med., 19, 499-504.

Troen, B.R. (2003) The biology of aging. Mount Sinai J. Med., 70, 3-22.

Vellas, B., Guigoz, Y., Baumgartner, M., Garry, P.J., Lauque, S. \& Albarede, J.L. (2000) Relationship between nutritional markers and the Mini-Nutritional Assessment in 155 older persons. J. Am. Geriatr. Soc., 48, 1300-1309.

Wickens, A.P. (2001) Ageing and the free radical theory. Respir. Physiol., 128, 379-391. 